\title{
POLÍTICAS DE COTAS NA UEPG: ANÁLISE DO ABANDONO E DO RENDIMENTO ACADÊMICO
}

(D) AUGUSTA PELINSKI RAIHER I

Universidade Estadual de Ponta Grossa (UEPG), Ponta Grossa-PR, Brasil; apelinski@gmail.com

\section{RESUMO}

Este artigo teve como objetivo avaliar o abandono e a eficiência (em termos de nota média) dos alunos cotistas versus os não cotistas da Universidade Estadual de Ponta Grossa (UEPG), subdividindo a análise entre licenciatura e bacharelado. Para isso, os alunos foram acompanhados durante pelo menos oito anos e, na sequência, aplicou-se o método Propensity Score Matching. Como corolário, não se encontrou diferença significativa entre o rendimento médio dos graduados cotistas versus os de entrada universal. No caso do abandono, constatou-se menor desistência dos alunos cotistas, especialmente quando se analisou os cursos de bacharelado.

PALAVRAS-ChAVE AÇÃO AFIRMATIVA • ABANDONO • RENDIMENTO ACADÊMICO • EDUCAÇÃO SUPERIOR. 


\section{POLÍTICAS DE CUOTAS EN UEPG: ANÁLISIS DE ABANDONO Y RENDIMIENTO ACADÉMICO}

\section{RESUMEN}

Este artículo tuvo como objetivo evaluar el abandono y la eficiencia (en términos de calificación promedio) de los estudiantes de cuota frente a los titulares no cuotistas de la Universidade Estadual de Ponta Grossa (UEPG), subdividiendo el análisis entre licenciatura y bachillerato. Para eso, los alumnos fueron seguidos durante al menos ocho años y luego aplicaron el método Propensity Score Matching. Como corolario, no hubo diferencias significativas entre el rendimiento promedio de los graduados de la cuota versus los de ingreso universal. En caso de abandono, se constató menor renuncia de los estudiantes cuotistas, especialmente cuando se analizaron los cursos de bachillerato.

PALABRAS CLAVE ACCIÓN AFIRMATIVA • ABANDONO • RENDIMIENTO ACADÉMICO • EDUCACIÓN SUPERIOR.

\section{QUOTA POLICIES AT THE UEPG: ANALYSIS OF DROPOUT AND ACADEMIC PERFORMANCE}

\section{ABSTRACT}

This article aimed to assess the dropout rate and efficiency (in terms of average grade) of quota students versus non-quota students at the Universidade Estadual de Ponta Grossa (UEPG), subdividing the analysis into teaching and bachelor's degrees. To do this, the students were followed for at least eight years. Subsequently, the Propensity Score Matching method was used. As a corollary, there was no significant difference between the average performance of quota graduates versus those with open admission. It was found that quota students had a lower dropout rate, especially when analyzing bachelor's courses.

KEYWORDS AFFIRMATIVE ACTION • DROPOUT • ACADEMIC ACHIEVEMENT • HIGHER EDUCATION. 


\section{INTRODUÇÃO}

A educação é um dos principais meios para se auferir o desenvolvimento econômico de uma região. Autores renomados, como Romer (1986) e Lucas (1988), demonstram o impacto da formação do capital humano no dinamismo econômico de uma região, afetando tanto a produtividade dos trabalhadores como a formação de tecnologias e sua difusão. No âmbito individual, evidências empíricas confirmam a superioridade de renda daqueles com maior escolaridade (BLOM; VERNER, 2001; FERNANDES; FILHO, 2000; etc.), especialmente os que têm ensino superior, que recebem, em média, o triplo de quem só têm ensino médio (INSTITUTO BRASILEIRO DE GEOGRAFIA E ESTATÍSTICA - IBGE, 2018).

O grande problema é que, em países com elevada desigualdade socioeconômica, o acesso ao nível superior de educação é bastante seletivo, como no caso brasileiro. De acordo com Andrade (2012), a maior parte das vagas de ensino superior do país tem sido acessada por alunos de alta renda, citando, como exemplo, o ano de 2009, quando $60 \%$ dos jovens do quintil mais rico ingressaram no ensino superior contra apenas 3\% do quintil mais pobre. Tem-se, portanto, uma desigualdade de oportunidade educacional no Brasil.

Se a população mais pobre tem dificuldades para acessar o ensino superior, dificilmente o círculo vicioso da pobreza será rompido, tornando-se um processo cumulativo intergeracional. Com efeito, diferentes estudos, como o de Vieira e Tenório (2014), demonstram que, quanto maior o nível socioeconômico da família e quanto mais elevada a escolaridade dos pais, o número de anos de estudo dos filhos tende a ser maior. Em termos de qualidade educacional, Lima e Silva et al. (2017) evidenciam um melhor desempenho no Exame Nacional do Ensino Médio (Enem) de estudantes que tinham pais com maior escolaridade e renda. Assim, o processo educacional se retroalimenta, intensificando as desigualdades no curso natural do seu desenvolvimento.

Por isso, políticas específicas são necessárias para romper esse círculo vicioso. E uma das ações afirmativas que tem esse intuito é a política de cotas, apresentando-se como provisória, com vistas a incentivar grupos desfavorecidos da sociedade a se inserir no ensino superior. Bittar e Almeida (2006) a descrevem como uma política de reparação histórica, que busca a justiça social, com um impacto bem mais profundo, afetando o desenvolvimento de toda a sociedade no longo prazo.

A primeira universidade brasileira a instituir tal ação foi a Universidade Estadual do Rio de Janeiro (UERJ), em 2003; em 2010, havia 83 instituições de ensino superior com essa política (GUARNIERI, 2008). Em 2012, foi aprovada a Lei de Cotas, a qual determina que as universidades, institutos e centros federais reservem $50 \%$ das suas vagas para estudantes oriundos de escola pública, com a garantia de um percentual específico para estudantes negros e indígenas. A Lei de Cotas sancionada 
após quase uma década de discussão, de certa maneira, representa uma validação de tal ação afirmativa, sendo hoje uma realidade garantida por lei.

Entretanto, não há ainda consenso na academia sobre a importância dessa política. Existe concordância de que o acesso à educação é desigual no Brasil e que é necessária uma maior inclusão; contudo não há concordância quanto à eficiência da política de cotas para que se atinja esse propósito. Alguns autores inferem que essa política não reduz a desigualdade, dado o despreparo dos alunos cotistas quando se inserem no ensino superior, ou a dificuldade financeira que eles têm para se sustentar, abandonando, em geral, o curso no decorrer do processo, ou não conseguindo formar profissionais bem preparados, gerando uma perda qualitativa de capital humano formado nas universidades (SOWELL, 2004; D'SOUZA, 1991); outros autores (MIRANDA, 2017; VALENTE; BERRY, 2017; WAINER; MELGUIZO, 2018) demonstram que não há custos para as universidades em termos de eficiência dos alunos cotistas, não existindo diferenças práticas entre o conhecimento dos estudantes não cotistas e cotistas, e, inclusive, os índices de evasão destes últimos são menores (SILVA, 2017; ARRIGONI, 2018). Os resultados desta pesquisa se apoiam na tese de Arrigoni (2018).

Nesse contexto, este artigo avalia o abandono e a eficiência (em termos de nota média) dos alunos cotistas versus os não cotistas, analisando dados da Universidade Estadual de Ponta Grossa (UEPG).

Outros autores já avaliaram a eficiência e a evasão dos alunos do ensino superior, como Santos e Queiroz (2010), Velloso e Cardoso (2008), Velloso (2009), Wainer e Melguizo (2018), Valente e Berry (2017), Silva (2017), entre outros, entretanto, não utilizaram a mesma metodologia usada nesta pesquisa, a qual acompanhou os alunos cotistas e não cotistas durante um período de até oito anos, analisando o abandono de cada grupo e o rendimento médio (nota média) dos graduados. Além desse diferencial, se utilizou o método Propensity Score Matching (PSM), o qual cria um grupo estatisticamente similar, de modo que o diferencial de notas ou de abandono se apoia apenas no fato de participar ou não da política de cotas e não em características endógenas dos estudantes.

Por fim, o terceiro ponto que diferencia este artigo é a análise separada que foi feita para os cursos de bacharelado e de licenciatura, tentando mensurar diferenças da política de cotas para cada um desses tipos de curso. Velloso (2009) destaca que a diplomação numa licenciatura não costuma conduzir a uma carreira socialmente valorizada, tendo, na média, menores salários do que os obtidos nos bacharelados, justificando a evasão superior. Coutinho et al. (2013) demonstram uma renda familiar superior especialmente para os cursos de tecnologia, os quais são, em sua maioria, cursos de bacharelado. Por isso, é necessário diferenciar os cursos e investigar o abandono e o rendimento acadêmico entre cotistas e não cotistas em cada grupo: licenciatura e bacharelado. 
Nesse sentido, este texto contribui diretamente para a discussão acerca da eficiência dos alunos cotistas versus os não cotistas, focando no rendimento e no abandono, usando metodologia específica para esse tipo de avaliação. Para isso, este artigo está estruturado em quatro seções, incluindo esta. Na segunda, apresenta-se a metodologia aplicada, seguida da análise e das conclusões finais.

\section{METODOLOGIA}

A Universidade Estadual de Ponta Grossa (UEPG) foi a instituição analisada neste estudo. Localizada no Paraná, foi a terceira a implantar a política de cotas no estado, iniciando as discussões em 2005, entrando em vigor a partir de 2007. Pela Resolução n. 9 de 26 de abril de 2006 (UNIVERSIDADE ESTADUAL DE PONTA GROSSA, 2006), ficou estabelecido que, no mínimo, $10 \%$ das vagas ofertadas em cada curso de graduação seriam destinadas aos candidatos oriundos de escolas públicas, e 5\%, para os provenientes de escolas públicas que se autodeclarassem negros. ${ }^{1}$ A resolução definiu um incremento anual de $5 \%$ da reserva para alunos de escolas públicas e de 1\% para os candidatos que se autodeclarassem negros.

É importante destacar que o ano inicial desta pesquisa foi 2009 (quando os alunos fizeram o vestibular) e os estudantes foram acompanhados durante oito anos (2010 a 2017), período que ultrapassa o prazo para a jubilação. Assim, os estudantes analisados fizeram vestibular em 2009 e iniciaram seu curso a partir de 2010. Ao todo, foram acompanhados $1.724^{2}$ estudantes, sendo $30 \%$ alunos cotistas, ressaltando que o mínimo que se deveria ter, conforme Resolução n. 9 de 26 de abril de 2006, era de 28\%. As informações foram obtidas junto à instituição a partir do cruzamento dos dados da Comissão Permanente de Seleção (CPS) e da Pró-Reitoria de Graduação (Prograd). Da primeira, foram obtidos os dados acerca da renda familiar dos alunos, se realizaram totalmente o ensino médio em escola pública, sua cor, sua nota na prova específica do vestibular e sua nota na prova de conhecimento geral; da segunda, foram coletados dados de abandono, curso de graduação, matrícula, trancamento, reprovações, notas médias durante o curso, se ingressante por cotas, gênero, curso e turno.

Inicialmente, fez-se uma análise exploratória da taxa de abandono dos alunos ingressantes do vestibular 2009, considerando toda a instituição, analisando, também, por setor, por turno (integral, matutino, vespertino ou noturno) e por tipo (licenciatura ou bacharelado). A mesma análise foi feita para a nota média, entretanto,

1 Entendia-se como candidato oriundo de escolas públicas aquele que realizou o ensino fundamental II (quinta a oitava série) e o ensino médio em escola pública, havendo tolerância para até dois anos cursados em outra escola não pública, exceto no ensino médio.

2 Ao todo, ingressaram 2.427 alunos no ano letivo de 2010, no entanto, excluiu-se da amostra os alunos que adentraram por transferências, e os com falta de alguma informação, especialmente os que não preencheram o questionário socioeconômico aplicado no ato do vestibular. 
avaliou-se apenas os alunos que concluíram o curso até 2017 (correspondendo a 1.105 alunos). Na sequência, usou-se o método PSM visando a avaliar a existência de diferenças entre cotistas (alunos provenientes de escola pública e os de escola pública que se autodeclaram negros) e não cotistas (que entraram pela seleção universal) no que se refere ao abandono de curso e ao rendimento acadêmico.

\section{Propensity Score Matching e estratégia empírica}

Uma forma eficiente para se avaliar o efeito de uma política pública sobre determinada variável consiste em observá-la quando a unidade de análise $i$ (neste caso, um acadêmico da UEPG ingressante em 2010) é beneficiada por determinada política versus quando não o é (HEINRICH; MAFFIOLI; VÁZQUEZ, 2010). A diferença obtida na variável de interesse consiste no impacto da política pública. Ou seja,

$$
\delta_{\mathrm{i}}=\Upsilon_{1 \mathrm{i}}-\Upsilon_{0 \mathrm{i}}
$$

em que $\delta_{i}$ é o efeito da política pública - neste caso, ser cotista - na variável de interesse (abandono e rendimento médio do acadêmico), em relação à unidade de análise (acadêmico) i; $\Upsilon_{1 \mathrm{i}}$ é o valor da variável de interesse após a participação do acadêmico $i$ na política; e $\Upsilon_{0 \mathrm{i}}$ denota o valor da variável de interesse se o acadêmico i não participasse da política de cotas.

O impacto de qualquer política pública não deve ser individualizado, seu efeito médio sobre o grupo analisado deve ser mensurado. Para isso, usa-se o parâmetro conhecido como Efeito Médio do Tratamento, Average Treatment Effect(ATE), descrito por:

$$
\operatorname{ATE}=\mathrm{E}(\delta)=\mathrm{E}\left(\Upsilon_{1}-\Upsilon_{0}\right)
$$

em que $E$ corresponde ao valor esperado; $\Upsilon_{1}$ é o valor da variável de interesse após a participação dos acadêmicos na política; e $\Upsilon_{0}$ denota o valor da variável de interesse caso os acadêmicos não participem da política.

A dificuldade de se mensurar (2) é que esse e outros efeitos não necessariamente são observáveis. Dessa forma, supondo que a diferença entre as médias seja dada pela média das diferenças, então ATE pode ser representado da seguinte maneira:

$$
\mathrm{ATE}=\mathrm{E}\left(\Upsilon_{1} \mid \mathrm{T}=1\right)-\mathrm{E}\left(\Upsilon_{0} \mid \mathrm{T}=1\right)
$$

em que o item $\mathrm{E}\left(\Upsilon_{0} \mid \mathrm{T}=1\right)$ representa o resultado médio que os tratados teriam obtido na ausência de tratamento, elemento que não é observado. Por isso, esse valor passa a ser substituído por $\mathrm{E}\left(\Upsilon_{0} \mid \mathrm{T}=0\right)$, mensurando o valor da variável de interesse, $\Upsilon_{0}$, do grupo dos não beneficiados pela política, o qual é observado. Com base nisso, pode-se calcular: 


$$
\Delta=\mathrm{E}\left(\Upsilon_{1} \mid \mathrm{T}=1\right)-\mathrm{E}\left(\Upsilon_{0} \mid \mathrm{T}=0\right)
$$

Se somar e subtrair de (4) o termo $\mathrm{E}\left(\Upsilon_{0} \mid \mathrm{T}=1\right)$, ter-se-á a diferença entre $\Delta$ e o ATE (5):

$$
\begin{aligned}
& \Delta=\mathrm{E}\left(\Upsilon_{1} \mid \mathrm{T}=1\right)-\mathrm{E}\left(\Upsilon_{0} \mid \mathrm{T}=1\right)+\mathrm{E}\left(\Upsilon_{0} \mid \mathrm{T}=1\right)-\mathrm{E}\left(\Upsilon_{0} \mid \mathrm{T}=0\right) \\
& \Delta=\mathrm{ATE}+\mathrm{E}\left(\Upsilon_{0} \mid \mathrm{T}=1\right)-\mathrm{E}\left(\Upsilon_{0} \mid \mathrm{T}=0\right) \\
& \Delta=\mathrm{ATE}+\mathrm{SB}
\end{aligned}
$$

em que SB corresponde à diferença entre a variável $\Upsilon$ do grupo dos beneficiados pela política de cotas e dos não beneficiados. Se $S B$ for igual a zero, $A T E$ pode ser mensurado pela diferença entre as médias da variável $\Upsilon$; no entanto, dificilmente isso ocorre, e, por isso, deve-se utilizar uma metodologia adequada que garanta que o termo $S B$ seja igual a zero.

Um dos métodos utilizados para minimizar o viés de seleção, especialmente quando a seleção dos participantes de determinado programa não é aleatória, ${ }^{3}$ é o PSM. Para isso, deve-se ter dois grupos: o de tratamento e o de controle. O primeiro é composto pelos indivíduos, no caso desta pesquisa, que se beneficiaram da política de cotas, e o segundo, pelos que não se beneficiaram.

A dificuldade que se tem de mensurar os efeitos da política de cotas entre esses dois grupos deve-se à distinção das características de ambos (como gênero, renda, conhecimento geral, conhecimento específico etc.), características que podem determinar a diferença da variável de interesse. A avaliação ideal do impacto de qualquer política pública seria a comparação entre um mesmo grupo em dois contextos: participar ou não de uma política. Porém, como isso não é possível, a alternativa está na criação de um grupo estatisticamente idêntico, de modo que o diferencial se apoie apenas no fato de participar ou não de uma política pública específica.

E o método PSM permite fazer essa comparação, encontrando os similares em grupos de acadêmico cotistas (grupo de tratamento, $\mathrm{T}=1$ ) e não cotistas (grupo de controle, $\mathrm{T}=0$ ). Essa propensão é gerada a partir das características observáveis dos alunos que afetam a sua probabilidade de participação na política. Nesta pesquisa, as características (denominadas de covariadas) utilizadas para esse pareamento foram: residir no Paraná (dummy “um” para se residia no estado, e “zero”, caso contrário); nota da prova específica (vocacional); nota da prova de conhecimento geral; se fez totalmente o ensino médio em escola pública ("um”, se sim; e "zero", caso contrário), cor ("um" se branco ou amarelo, e "zero", se não); setor de conhecimento;"

3 Dada a não aleatoriedade, não se consegue separar o efeito do programa dos efeitos de outros fatores que também podem influenciar a variável de interesse.

4 Inseriu-se uma dummy (variável binária) para cada setor de conhecimento. 
turno ("zero" para integral, matutino ou vespertino, e "um" para noturno); gênero ("um" para masculino, e "zero" para feminino).

Cabe ressaltar que, ao buscar similares quando se tem diferentes características elencadas, incorre-se, possivelmente, no problema da multidimensionalidade, ou seja, o acadêmico $i$ pode ter algumas características próximas do jovem $j$, e outras, de $m$. Nesse caso, a dificuldade estaria em estabelecer com quem $i$ deveria ser comparado. O PSM minimiza esse problema, calculando a probabilidade de o aluno receber o tratamento levando em consideração as suas características observáveis (covariadas). Nesta pesquisa, essa probabilidade foi mensurada pela aplicação do modelo Logit, com o pareamento (matching) baseado no pressuposto de independência condicional:

$$
\mathrm{P}\left(\mathrm{T}_{\mathrm{i}}=1 \mid \mathrm{X}_{\mathrm{i}}\right)=\frac{1}{1+\mathrm{e}^{-\mathrm{x}^{\prime} \beta}{ }_{\mathrm{i}}}
$$

em que $\mathrm{P}\left(\mathrm{T}_{\mathrm{i}}=1 \mid \mathrm{X}_{\mathrm{i}}\right)$ denota a probabilidade de o aluno ser cotista, considerando suas covariadas.

Como consequência desse pressuposto, a diferença entre as médias das covariadas do grupo de tratamento e de controle não podem ser estatisticamente diferentes de zero.

Na sequência, pelo método PSM, pareiam-se ${ }^{5}$ os alunos com escores iguais ou próximos e, em seguida, avalia-se se o abandono e o rendimento acadêmico (notas médias durante todo o curso) do grupo de tratamento são estatisticamente superiores aos do grupo de controle.

Foi feito o PSM para todos os alunos da UEPG ingressantes em 2010, analisando o abandono e o rendimento médio; depois, fez-se as mesmas análises agrupando os cursos de Licenciatura e Bacharelado, identificando as diferenças.

Ademais, como teste de balanceamento, fez-se o teste de médias e o teste de distribuição Kolmogorov-Smirnov, cuja hipótese nula é de que o grupo de tratamento e o grupo de controle são estatisticamente iguais. É importante destacar a necessidade de discrepância das covariadas selecionadas entre os grupos antes do pareamento. Portanto aquelas variáveis que não atenderam a essa exigência não foram incluídas no pareamento.

Ainda sobre as estimações realizadas, tendo em vista o tamanho satisfatório da base de dados utilizada, foi possível fazer uso de opções mais restritivas em relação à formação do grupo de controle, com destaque para a utilização do critério de

5 Ressalta-se que o pareamento (matching) foi realizado por meio do algoritmo do vizinho mais próximo (três vizinhos com reposição), com a ratificação dos dados por meio do caliper 0,01, enfatizando que o primeiro método se apresentou como o mais adequado, dada a similaridade observada para a propensão do grupo de controle e tratado após o pareamento, evidenciado por meio da função de densidade do Propensity Score (Apêndice). 
suporte comum e a imposição adicional de descarte (trimming) em 10\% das observações do grupo de tratamento que coincidiram com as menores densidades do escore de propensão dos controles, ação que não alterou os resultados iniciais.

\section{O ABANDONO E A EFICIÊNCIA (EM TERMOS DE NOTA MÉDIA) DOS ALUNOS COTISTAS VERSUS OS NÃO COTISTAS}

Conforme o Gráfico 1, a renda familiar da maioria dos estudantes da UEPG se situava nas faixas de três a dez salários-mínimos no ano de 2009. A distribuição de estudantes cotistas e de entrada universal por faixa de renda mostra maior concentração dos primeiros até a faixa de quatro salários, invertendo tal situação a partir da faixa seguinte. Destarte, 79\% dos alunos cotistas tinham renda familiar de até cinco salários-mínimos, enquanto que, entre os de entrada universal, o percentual era de apenas $49 \%$.

Assim, a diferença de renda entre cotistas e não cotistas era real, com superioridade destes últimos, embora não fosse tão discrepante como evidenciado em outros estudos. Por exemplo, Nascimento e Pereira (2014), ao analisarem o perfil dos cotistas da Universidade Federal da Bahia, em 2009, constataram que 81\% tinham renda familiar de até cinco salários-mínimos, contra 40\% dos não cotistas, diferença um pouco maior que a observada na UEPG.

\section{GRÁFICO 1 - Distribuição percentual dos estudantes cotistas e de entrada universal na UEPG em 2009, por faixa de renda familiar}

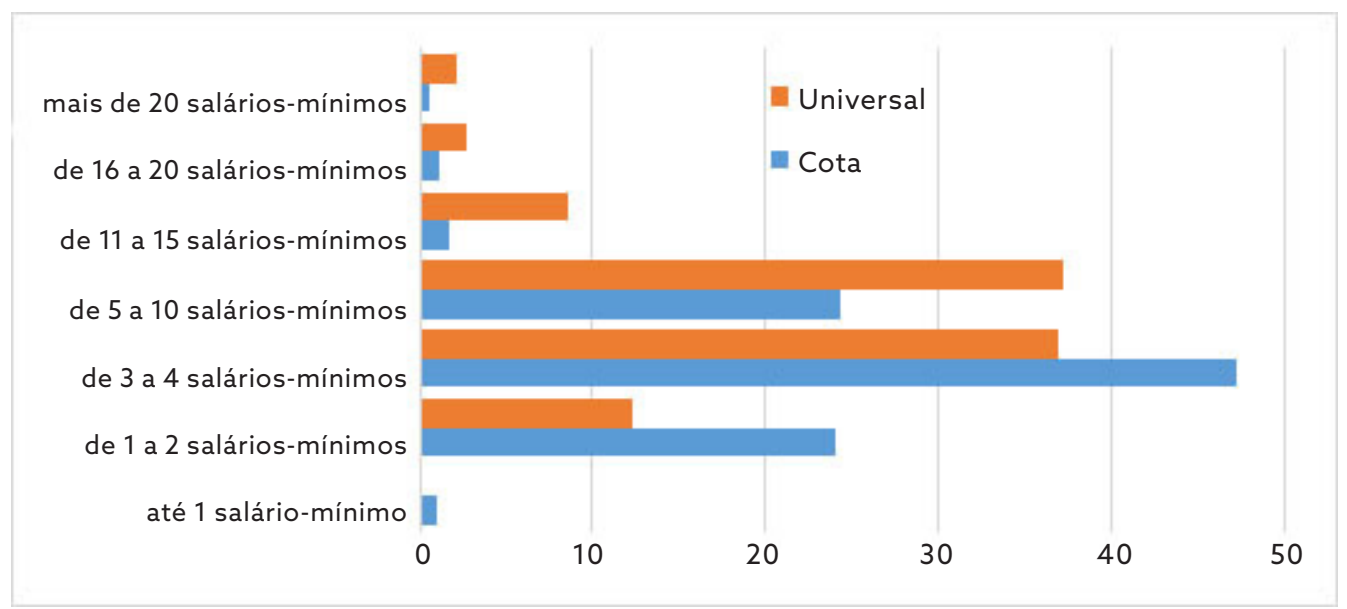

Fonte: Elaboração da autora com base em dados da UEPG.

Em investigações posteriores, será importante entender as características desses $49 \%$ dos estudantes de entrada universal que tinham renda familiar de até cinco salários-mínimos e que não optaram ou não puderam concorrer à cota de vagas. Eram estudantes com renda familiar similar à maioria dos cotistas, relativamente baixa, e que, portanto, estariam dentro do grupo da instituição mais vulnerável 
economicamente. Talvez o parâmetro de apenas "ser de escola pública", sem ter um gatilho para beneficiar quem tenha renda baixa, seja um dos fatores que deixou à margem da política esse grupo. Também pode ter sido escolha própria dos estudantes, por ver em alguns cursos maior concorrência entre os cotistas do que entre os não cotistas, ${ }^{6}$ ou pode ser desinformação quanto à possibilidade da entrada via políticas de cotas. O importante é tentar identificar o porquê dessa opção dos estudantes, visando a tornar a política ainda mais inclusiva.

Dividindo os cursos em licenciatura e bacharelado (Gráfico 2), observa-se que entre os cotistas que faziam cursos de licenciatura, cerca de $80 \%$ estavam nas faixas de menor renda, e apenas 18,2\% estavam nas faixas acima de quatro salários, enquanto entre os cotistas que faziam bacharelado esse percentual era de 31,9\%. No caso dos não cotistas cursando licenciatura, 31,6\% estavam nas faixas acima de quatro salários, ao passo que os dos cursos de bacharelado correspondiam a 58,4\%.

Portanto, percebe-se uma predominância dos alunos de licenciatura cotistas nas menores faixas de renda mais baixa, constituindo o grupo mais vulnerável economicamente da instituição. Queiroz (2004), ao analisar os alunos negros e brancos da Universidade Federal da Bahia, infere que, quando se tem baixa expectativa de se entrar na universidade, valoriza-se mais o curso, e não se tem prioridade na escolha dos cursos de maior prestígio, escolhendo, especialmente, os cursos de licenciatura, de menor concorrência.

\section{GRÁFICO 2 - Distribuição percentual dos estudantes da UEPG em 2009, quanto ao tipo de curso e de seleção, por faixa de renda familiar}

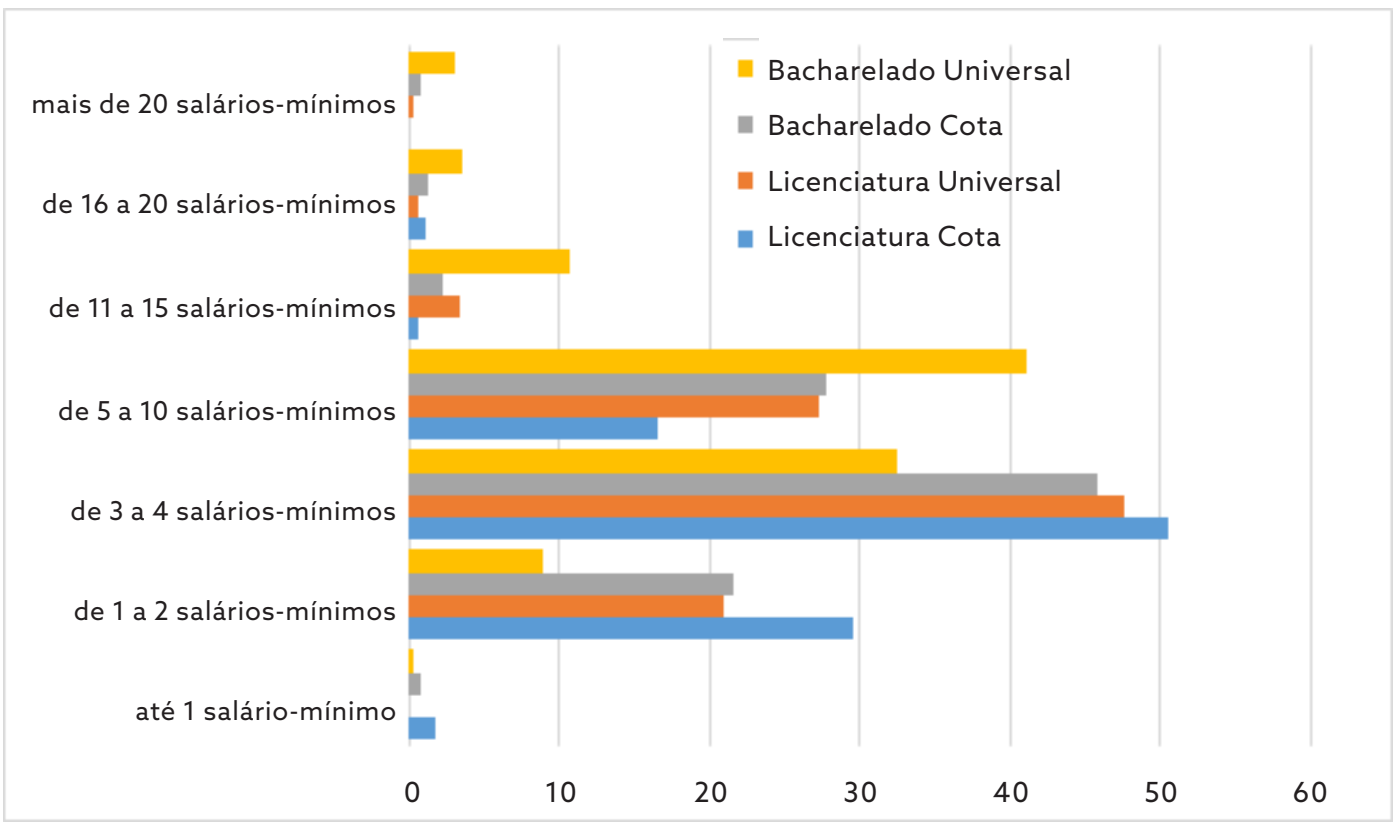

Fonte: Elaboração da autora com base em dados da UEPG.

6 Dos 34 cursos ofertados para ingresso pelo exame vestibular de 2009, 20 tinham uma concorrência igual ou maior para os cotistas do que para os candidatos de entrada universal. 
Considerando os diferentes setores de conhecimento da UEPG (Tabela 1), os alunos cotistas apresentaram média de renda familiar menor que a dos não cotistas em todos os setores, com menor diferença entre cotistas e não cotistas no setor de “Ciências Exatas e Naturais" (3,21; 3,85). Ressalta-se que as menores médias de renda familiar de cotistas e de não cotistas são as apresentadas por alunos dos setores de "Ciências Exatas e Naturais" (3,21; 3,85) e de "Ciências Humanas e Artes" (3,00; $3,85)$, que também apresentam as menores diferenças entre as médias dos cotistas e dos não cotistas.

Essas informações ratificam os achados anteriores, confirmando a superioridade de renda dos alunos não cotistas, especialmente dos que fazem os cursos de bacharelado.

De modo geral, esses resultados iniciais demonstram que o público atendido pela UEPG em 2010 era, na sua maioria, de alunos de baixa renda, evidenciando o papel social da instituição.

Para uma verificação mais apurada, analisou-se a renda média familiar (em termos do número de salários-mínimos) dos estudantes de cada curso e a concorrência no exame vestibular de 2009. Em 95\% dos cursos, a renda média familiar dos cotistas era inferior à dos não cotistas; ao mesmo tempo, não se tinha uma discrepância significativa no número de candidatos por vaga entre os cotistas e os não cotistas, de modo que, em 35\% dos cursos, foi observado um número maior de candidatos por vaga no grupo cotista do que no de entrada universal. ${ }^{7}$ Nesse sentido, o argumento de que a concorrência por vaga dos que entram por cota é menor não necessariamente é verdadeiro.

TABELA 1 - Renda média familiar, em número de salários-mínimos, dos alunos da UEPG em 2009, quanto ao tipo de seleção e setor de conhecimento

\begin{tabular}{l|c|c}
\multicolumn{1}{c|}{ SETOR } & UNIVERSAL & COTAS \\
\hline Ciências Exatas e Naturais & 3,85 & 3,21 \\
Ciências Agrárias e de Tecnologia & $\mathbf{5 , 1 2}$ & 3,62 \\
Ciências Biológicas e da Saúde & $\mathbf{5 , 1 4}$ & 3,68 \\
Ciências Sociais Aplicadas & $\mathbf{4 , 8 5}$ & 3,46 \\
Ciências Humanas, Letras e Artes & $\mathbf{3 , 8 5}$ & 3,00 \\
Ciências Jurídicas & $\mathbf{6 , 6 1}$ & 4,98 \\
\hline Total & $\mathbf{4 , 7 4}$ & 3,53 \\
\hline
\end{tabular}

Fonte: Elaboração da autora com base em dados da UEPG.

7 Em 50\% dos cursos, a concorrência dos não cotistas era maior que a dos cotistas, e, em 15\%, era igual. 
Ao subdividir os cursos em licenciatura e bacharelado (Tabela 2), confirma-se que a renda média dos alunos que cursavam licenciatura era inferior, e, ao mesmo tempo, que os cursos de licenciatura tinham a menor média de número de candidatos por vaga. Diniz-Pereira (2011), ao analisar uma universidade específica na década de 1990, também evidenciou essa tendência de os aprovados nos cursos de licenciatura terem menor renda do que os alunos que optavam por outros cursos. Ademais, o autor argumentou que essa menor concorrência por vaga representa a própria realidade de parte desses cursos, com rendas futuras menores do que a dos cursos mais concorridos. Igualmente, Coutinho et al. (2013) também verificaram uma renda familiar inferior de alunos dos cursos de licenciatura quando em comparação aos de cursos de graduação em tecnologia de um dos polos de apoio presencial da Serra Gaúcha. Carvalhaes e Ribeiro (2019), ao investigarem todos os cursos de ensino superior entre 2002 e 2010 no Brasil, evidenciaram uma concentração de estudantes com renda maior em cursos com elevados retornos econômicos, enquanto os estudantes em situação de maior vulnerabilidade socioeconômica concentraram-se especialmente nos cursos com menores retornos. Destes últimos, a maioria era de cursos de licenciatura. Para Diniz-Pereira (2011), as políticas públicas educacionais têm grande responsabilidade nessa realidade, não se traduzindo em melhorias efetivas das condições salariais e de trabalho dos docentes, sendo apenas um discurso demagógico de valorização.

Quando analisada a média de renda familiar do número de candidatos por vaga entre os cursos de licenciatura e de bacharelado, subdividindo-os por cotas e entrada universal, na média se tinha uma concorrência maior e uma renda menor para o grupo dos cotistas em todos os casos (Tabela 2). Isso desmistifica a hipótese do senso comum acerca da menor concorrência que os estudantes cotistas enfrentam, apresentando, tanto na média dos cursos de licenciatura como de bacharelado, um maior número de candidatos por vaga. A diferença é que os cotistas concorrem entre si, não sendo desleal a competição, dada a qualidade educacional auferida ex ante em cada grupo.

TABELA 2 - Média da renda familiar dos estudantes da UEPG e do número de candidatos por vaga no vestibular de 2009, segundo o tipo de seleção e de curso

\begin{tabular}{|c|c|c|c|c|}
\hline \multirow{2}{*}{ CURSOS } & \multicolumn{2}{|c|}{$\begin{array}{c}\text { RENDA FAMILIAR } \\
\text { (NDE SALÁRIOS-MÍNIMOS) }\end{array}$} & \multicolumn{2}{|c|}{$\begin{array}{l}\text { NÚMERO DE CANDIDADOS } \\
\text { POR VAGA }\end{array}$} \\
\hline & UNIVERSAL & COTAS & UNIVERSAL & COTAS \\
\hline Bacharelado & 5,1 & 3,5 & 12,2 & 12,7 \\
\hline Licenciatura & 3,7 & 2,9 & 7,9 & 8,2 \\
\hline
\end{tabular}

Fonte: Elaboração da autora com base em dados da UEPG. 


\section{Abandono e rendimento médio}

De todos os alunos que entraram na UEPG em 2010, 24,7\% deles abandonaram o curso até 2018, sendo $24 \%$ entre os cotistas e $25 \%$ entre os não cotistas. Reunindo o abandono e o trancamento, a taxa de evasão fica em $26,7 \%$, sendo $27,5 \%$ dos não cotistas e $25 \%$ dos cotistas. Dos que entraram e não abandonaram e nem trancaram, 64\% concluíram o curso até 2018, sendo 63\% de não cotistas e 66\% de cotistas (Tabela 3). Nesse escopo, os resultados gerais mostram um abandono menor e uma proporção maior de concluintes no grupo dos cotistas.

Ao analisar os diferentes setores de conhecimento, em praticamente todos, os cotistas detinham menor abandono/trancamento, e, na maioria deles, apresentavam uma proporção maior de concluintes (Tabela 3). Portanto, esses são elementos que sinalizam um menor prejuízo em termos de vagas desperdiçadas (abandonadas) pelos alunos cotistas, desmistificando possíveis ônus em termos de desistências dos cursos.

TABELA 3 - Percentagem de alunos da UEPG de 2010 a 2018 por sua situação em relação ao curso, segundo o tipo de seleção e o setor de conhecimento

\begin{tabular}{|c|c|c|c|c|c|c|}
\hline \multirow{2}{*}{ SETOR } & \multicolumn{2}{|c|}{$\begin{array}{l}\text { ABANDONO OU } \\
\text { TRANCAMENTO }\end{array}$} & \multicolumn{2}{|c|}{ GRADUADOS } & \multicolumn{2}{|c|}{ MATRICULADOS } \\
\hline & UNIVERSAL & COTAS & UNIVERSAL & COTAS & UNIVERSAL & COTAS \\
\hline Ciências Agrárias e de Tecnologia & 24,5 & 23,5 & 70,0 & 67,6 & 5,5 & 8,8 \\
\hline Ciências Biológicas e da Saúde & 28,2 & 21,8 & 66,2 & 73,4 & 5,6 & 4,8 \\
\hline Ciências Exatas e Naturais & 42,2 & 35,9 & 37,7 & 46,2 & 20,1 & 17,9 \\
\hline Ciências Humanas, Letras e Artes & 24,9 & 29,4 & 62,4 & 61,2 & 12,7 & 9,4 \\
\hline Ciências Jurídicas & 12,1 & 8,2 & 84,6 & 81,6 & 3,3 & 10,2 \\
\hline Ciências Sociais Aplicadas & 27,7 & 26,4 & 61,8 & 66,2 & 10,5 & 7,4 \\
\hline TOTAL & 27,5 & 25,1 & 62,8 & 65,9 & 9,7 & 9,0 \\
\hline
\end{tabular}

Fonte: Elaboração da autora com base em dados da UEPG.

Classificando os estudantes de acordo com o tipo do curso - licenciatura ou bacharelado (Tabela 4) -, a porcentagem de abandono ou trancamento permanece menor entre os cotistas enquanto a de concluintes é maior nesse grupo, embora a diferença do abandono ou trancamento entre cotistas e não cotistas tenha sido menor nos cursos de licenciatura do que nos de bacharelado.

Ao se analisar a taxa geral de evasão do bacharelado e da licenciatura, a segunda apresenta o maior valor. Mazzetto e Carneiro (2002) inferem que a conclusão de cursos de licenciatura não necessariamente conduz a uma carreira socialmente valorizada (em termos de salário e valorização social), o que justificaria a evasão mais alta do que a observada em cursos de bacharelado. 
TABELA 4 - Porcentagem de alunos da UEPG de 2010 a 2018 por sua situação em relação ao curso, segundo o tipo de seleção e de curso

\begin{tabular}{l|c|c|c|c|c|c|}
\hline \multirow{2}{*}{ TIPO DE CURSO } & \multicolumn{2}{c|}{\begin{tabular}{c}
\multicolumn{2}{c|}{ ABANDONO OU } \\
TRANCAMENTO
\end{tabular}} & \multicolumn{2}{c|}{ GRADUADOS } & \multicolumn{2}{c}{ MATRICULADOS } \\
\cline { 2 - 7 } & UNIVERSAL & COTAS & UNIVERSAL & COTAS & UNIVERSAL & COTAS \\
\hline Bacharelado & $\mathbf{2 6 , 8}$ & 23,8 & 65,5 & $\mathbf{6 8 , 9}$ & $\mathbf{7 , 7}$ & $\mathbf{7 , 4}$ \\
Licenciatura & $\mathbf{2 9 , 3}$ & 28,1 & 56,2 & $\mathbf{5 9 , 0}$ & $\mathbf{1 4 , 5}$ & 12,9 \\
\hline
\end{tabular}

Fonte: Elaboração da autora com base em dados da UEPG.

Ao se classificar os estudantes conforme o turno do curso (integral, matutino, vespertino ou noturno), foram observadas taxas de abandono ou trancamento menores para os alunos cotistas, especialmente nos cursos integrais e matutinos. No turno noturno, praticamente não se verificou diferença de abandono ou trancamento de alunos cotistas e não cotistas, demonstrando um perfil similar desses dois grupos. No caso dos cursos vespertinos, houve o maior abandono, tanto de não cotistas como de cotistas. Talvez a crise vivenciada pelo país após 2013 tenha afetado esses números, especialmente os referentes a alunos que estudavam no período vespertino.

TABELA 5 - Porcentagem de alunos da UEPG de 2010 a 2018 por sua situação em relação ao curso, segundo o tipo de seleção e o turno

\begin{tabular}{|c|c|c|c|c|c|c|}
\hline \multirow{2}{*}{ TURNO } & \multicolumn{2}{|c|}{$\begin{array}{l}\text { ABANDONO OU } \\
\text { TRANCAMENTO }\end{array}$} & \multicolumn{2}{|c|}{ GRADUADO } & \multicolumn{2}{|c|}{ MATRICULADO } \\
\hline & UNIVERSAL & COTAS & UNIVERSAL & COTAS & UNIVERSAL & COTAS \\
\hline Integral & 27,5 & 21,3 & 67,3 & 74,3 & 5,2 & 4,5 \\
\hline Matutino & 26,1 & 22,1 & 63,9 & 68,6 & 10,0 & 9,3 \\
\hline Vespertino & 29,2 & 37,5 & 58,5 & 62,5 & 12,3 & 0,0 \\
\hline Noturno & 27,8 & 27,9 & 58,6 & 59,2 & 13,7 & 12,9 \\
\hline
\end{tabular}

Fonte: Elaboração da autora com base em dados da UEPG.

A elaboração da Tabela 6, com base no cruzamento de variáveis das tabelas 4 e 5, permitiu observar que o menor abandono que se tinha entre os cotistas nos cursos integrais e matutinos se dava especialmente nos cursos de bacharelado, e não de licenciatura (Tabela 6). Nos cursos vespertinos, que tiveram a maior taxa de abandono (Tabela 5), os cursos de bacharelado apresentaram maior desistência, retendo apenas 20\% dos seus alunos cotistas e 53\% dos não cotistas. 
TABELA 6 - Porcentagem de alunos da UEPG de 2010 a 2018 por sua situação em relação ao curso, segundo o tipo de seleção, de curso e turno

\begin{tabular}{|c|c|c|c|c|c|c|}
\hline \multirow{2}{*}{ SELEÇÃO } & \multirow{2}{*}{ CURSO } & \multirow{2}{*}{$\begin{array}{c}\text { SITUAÇÃO } \\
2018\end{array}$} & \multicolumn{4}{|c|}{ TURNO } \\
\hline & & & INTEGRAL & MATUTINO & VESPERTINO & NOTURNO \\
\hline \multirow{6}{*}{ Cotas } & \multirow{3}{*}{ Licenciatura } & $\begin{array}{l}\text { Abandono+ } \\
\text { trancamento }\end{array}$ & 80,0 & 23,1 & 7,1 & 29,2 \\
\hline & & Graduado & 0,0 & 61,5 & 92,9 & 57,6 \\
\hline & & Matriculado & 20,0 & 15,4 & 0,0 & 13,2 \\
\hline & \multirow{3}{*}{ Bacharelado } & $\begin{array}{l}\text { Abandono+ } \\
\text { trancamento }\end{array}$ & 19,8 & 21,9 & 80,0 & 26,6 \\
\hline & & Graduado & 76,1 & 69,9 & 20,0 & 60,9 \\
\hline & & Matriculado & 4,1 & 8,2 & 0,0 & 12,5 \\
\hline \multirow{6}{*}{ Universal } & \multirow{3}{*}{ Licenciatura } & $\begin{array}{l}\text { Abandono+ } \\
\text { trancamento }\end{array}$ & 44,4 & 20,0 & 22,9 & 30,3 \\
\hline & & Graduado & 44,4 & 60,0 & 68,8 & 53,9 \\
\hline & & Matriculado & 11,1 & 20,0 & 8,3 & 15,7 \\
\hline & \multirow{3}{*}{ Bacharelado } & $\begin{array}{l}\text { Abandono+ } \\
\text { trancamento }\end{array}$ & 27,0 & 26,7 & 47,1 & 24,5 \\
\hline & & Graduado & 67,9 & 64,2 & 29,4 & 64,5 \\
\hline & & Matriculado & 5,1 & 9,1 & 23,5 & 11,0 \\
\hline
\end{tabular}

Fonte: Elaboração da autora com base em dados da UEPG.

A análise por curso revelou heterogeneidade nas taxas de abandono, que variaram significativamente, inclusive dentro do próprio setor de conhecimento. Destaque deve ser dado ao curso de Medicina, que apresentou 0\% de abandono e trancamento tanto de cotistas como de não cotistas. Ao se correlacionar a taxa de evasão por curso com o número de candidatos por vaga, foi obtido o valor de $-0,47$ para os não cotistas e de -0,29 para os cotistas, indicando que, quanto maior o número de candidatos por vaga, menor tende a ser o abandono, e vice-versa. Da mesma forma, ao se analisar o abandono por curso em relação à renda familiar, para os não cotistas se identificou um coeficiente de correlação negativo e significativo $(-0,37)$, indicando que os cursos com maior taxa de abandono tinham, na média, estudantes com renda familiar menor, e vice-versa. Mas, no caso dos cotistas, a correlação não foi estatisticamente significativa $(-0,08)$, não estando associada a renda familiar à taxa de abandono.

Isso é corroborado pelos números apresentados na Tabela 7, em que se observa que não necessariamente faixas de renda familiar mais altas indicam menor taxa de abandono de cotistas. Já no caso de não cotista, percebe-se certa associação entre abandono e renda, taxa decrescente de evasão conforme se eleva a faixa de renda familiar. 
TABELA 7 - Porcentagem de alunos da UEPG, selecionados pelo vestibular de 2009, que abandonaram o curso de 2010 a 2018, segundo o tipo de seleção e a faixa de renda familiar

\begin{tabular}{lcc}
\multicolumn{1}{c}{ FAIXA DE RENDA FAMILIAR } & COTA & UNIVERSAL \\
\hline Até 1 salário-mínimo & 50,0 & 50,0 \\
De 1 a 2 salários-mínimos & 17,9 & 30,7 \\
De 3 a 4 salários-mínimos & 27,2 & 27,6 \\
De 5 a 10 salários-mínimos & 21,1 & 23,4 \\
De 11 a 15 salários-mínimos & 10,0 & 20,4 \\
De 16 a 20 salários-mínimos & 28,6 & 19,4 \\
Mais de 20 salários-mínimos & 0,0 & 16,0 \\
\hline
\end{tabular}

Fonte: Elaboração da autora com base em dados da UEPG.

Um segundo elemento que é objeto desta análise é o rendimento dos alunos ao longo do curso. Para isso, considerou-se apenas os alunos graduados e analisou-se suas notas. Na Tabela 8, tem-se a média de rendimento por setor de conhecimento, em que, embora quase todos os cotistas tenham uma média maior, a diferença era mínima, não sendo estatisticamente significativa. Isso se reflete na média institucional, a qual é igual tanto para cotistas como para não cotistas (nota média igual a 7,5).

TABELA 8 - Média das notas dos alunos graduados pela UEPG de 2010 a 2018 por tipo de seleção e setor de conhecimento

\begin{tabular}{l|c|c}
\multicolumn{1}{c}{ SETOR } & \multicolumn{2}{c}{ GRADUADO } \\
\cline { 2 - 3 } & COTAS & UNIVERSAL \\
Ciências Exatas e Naturais & $\mathbf{7 , 3}$ & $\mathbf{7 , 2}$ \\
Ciências Agrárias e de Tecnologia & $\mathbf{7 , 1}$ & $\mathbf{6 , 9}$ \\
Ciências Biológicas e da Saúde & $\mathbf{7 , 7}$ & $\mathbf{7 , 5}$ \\
Ciências Sociais Aplicadas & $\mathbf{7 , 5}$ & $\mathbf{7 , 7}$ \\
Ciências Humanas, Letras e Artes & $\mathbf{8 , 0}$ & $\mathbf{8 , 0}$ \\
Ciências Jurídicas & 7,5 & $\mathbf{7 , 9}$ \\
\hline \multicolumn{1}{c}{ TOTAL } & $\mathbf{7 , 5}$ & $\mathbf{7 , 5}$ \\
\hline
\end{tabular}

Fonte: Elaboração da autora com base em dados da UEPG.

Na Tabela 9, apresenta-se a nota média por tipo de curso (licenciatura ou bacharelado) em diferentes turnos cursados. Novamente, a disparidade entre cotistas e não cotistas, tanto na licenciatura como no bacharelado, eram mínimas, com valores um pouco maiores para os cursos de bacharelado. No caso da licenciatura, as notas médias de cotistas eram maiores ou iguais às notas dos não cotistas. Ou seja, não existiam diferenças significativas no que se refere ao rendimento acadêmico de alunos cotistas e não cotistas. 
TABELA 9 - Média das notas de alunos graduados pela UEPG de 2010 a 2018 segundo o tipo de curso, de seleção e turno

\begin{tabular}{l|cc|c|c|cc}
\hline \multirow{2}{*}{ TURNO } & \multirow{2}{*}{ UNIVERSAL } & \multirow{2}{*}{ COTAS } & \multicolumn{2}{c|}{ LICENCIATURA } & \multicolumn{2}{c}{ BACHARELADO } \\
\cline { 4 - 7 } & & UNIVERSAL & COTAS & UNIVERSAL & COTAS \\
\hline Integral & 7,3 & 7,4 & 6,9 & - & 7,3 & 7,4 \\
Matutino & 7,8 & 7,7 & 8,2 & 8,4 & 7,8 & 7,5 \\
Vespertino & 7,6 & 7,8 & 7,7 & 7,7 & 7,5 & 8,1 \\
Noturno & 7,7 & 7,5 & 7,6 & 7,6 & 7,7 & 7,4 \\
\hline Total & 7,52 & 7,52 & 7,6 & 7,7 & 7,5 & 7,4 \\
\hline
\end{tabular}

Fonte: Elaboração da autora com base em dados da UEPG.

É interessante observar que, nas faixas de renda familiar mais baixas (até quatro salários-mínimos), o desempenho acadêmico dos cotistas era superior ou igual aos dos não cotistas. Entre 11 e 20 salários-mínimos, na média, não se tinha diferenças entre os grupos, e, acima desse valor, a disparidade existia, no entanto, era mínima (apenas 0,4 pontos na média).

TABELA 10 - Nota média dos alunos graduados pela UEPG de 2010 a 2018 segundo o tipo de seleção e a faixa de renda familiar em 2009

\begin{tabular}{lcc}
\multicolumn{1}{c}{ FAIXA DE RENDA FAMILIAR } & COTA & UNIVERSAL \\
\hline Até um salário-mínimo & $\mathbf{6 , 5}$ & 5,3 \\
De 1 a 2 salários-mínimos & $\mathbf{7 , 4}$ & $\mathbf{7 , 4}$ \\
De 3 a 4 salários-mínimos & $\mathbf{7 , 6}$ & $\mathbf{7 , 5}$ \\
De 5 a 10 salários-mínimos & 7,5 & $\mathbf{7 , 6}$ \\
De 11 a 15 salários-mínimos & $\mathbf{7 , 5}$ & $\mathbf{7 , 5}$ \\
De 16 a 20 salários-mínimos & $\mathbf{7 , 5}$ & $\mathbf{7 , 5}$ \\
Mais de 20 salários-mínimos & $\mathbf{6 , 9}$ & $\mathbf{7 , 3}$ \\
\hline
\end{tabular}

Fonte: Elaboração da autora com base em dados da UEPG.

Diante dessas análises exploratórias, pode-se dizer que a evasão de cotistas era, na média, menor do que a de não cotistas, e, no caso do rendimento acadêmico, havia uma diferença pequena, oscilando bastante a depender do turno, do tipo do curso e da faixa de renda de cada graduado. Na subseção seguinte, apresenta-se testes mais robustos para identificar a existência de disparidades quanto ao abandono e ao rendimento acadêmico de alunos que entraram pelo sistema de cotas e os que concorreram por vaga universal. 
Propensity Score Matching: evidências empíricas para o sistema de cotas no abandono e no rendimento acadêmico da UEPG

As análises preliminares sinalizam uma diferença pequena entre o rendimento acadêmico dos não cotistas e dos cotistas, verificando-se taxa de evasão menor para esses últimos. A questão é que nessas análises trabalhou-se com médias entre os grupos, sem considerar as características individuais que podem afetar tanto o abandono do curso como o rendimento individual. Por isso, a utilização do método PSM apresenta-se como a melhor alternativa para se ter resultados mais robustos, especialmente por considerar as características individuais (covariadas) na determinação das diferenças existentes entre esses dois grupos (cotistas e não cotistas).

Nesse contexto, o primeiro passo para a aplicação do método consiste em dividir o conjunto dos acadêmicos em tratados (aqueles que participaram da política de cotas) e grupo de controle (aqueles que não participaram da política), verificando se as características de ambos os grupos eram similares.

Os resultados demonstraram que, com exceção do setor de conhecimento e da cor, todas as variáveis consideradas apresentaram diferenças significativas entre as médias, evidenciando que as características eram diferentes em ambos os grupos (Tabela 11). ${ }^{8}$

TABELA 11 - Teste $t$ para a diferença de médias entre as variáveis covariadas antes do pareamento e após o pareamento - Abandono (a); rendimento (b) - acadêmicos da UEPG ingressantes em 2010

\begin{tabular}{|c|c|c|c|c|}
\hline \multirow[b]{2}{*}{ COVARIÁVEIS } & \multicolumn{2}{|c|}{ ABANDONO (A) } & \multicolumn{2}{|c|}{ RENDIMENTO (B) } \\
\hline & $\begin{array}{l}\text { ANTES DO } \\
\text { PAREAMENTO }\end{array}$ & $\begin{array}{l}\text { DEPOIS DO } \\
\text { PAREAMENTO }\end{array}$ & $\begin{array}{c}\text { ANTES DO } \\
\text { PAREAMENTO }\end{array}$ & $\begin{array}{l}\text { DEPOIS DO } \\
\text { PAREAMENTO }\end{array}$ \\
\hline Prova específica (vocacional) & $5,78^{*}$ & 0,52 & $4,86^{*}$ & 1,63 \\
\hline Prova de conhecimento geral & $5,57 *$ & $-0,29$ & $4,82 *$ & 1,88 \\
\hline Renda familiar & $10,13 *$ & $-1,44$ & $8,38 *$ & 0,45 \\
\hline $\begin{array}{l}\text { Dummy escola pública ( } 1 \text { para ensino } \\
\text { médio feito totalmente em escola } \\
\text { pública) }\end{array}$ & $35,81^{*}$ & 0,00 & $34,09 *$ & 0,00 \\
\hline Cor ( 1 se branco/amarelo, 0 se não) & 0,47 & - & 0,50 & - \\
\hline Setor de conhecimento & 0,33 & - & 0,93 & - \\
\hline $\begin{array}{l}\text { Turno ( } 0 \text { integral/matutino/ } \\
\text { vespertino, } 1 \text { noturno) }\end{array}$ & $-2,34 *$ & $-1,08$ & $-1,09$ & - \\
\hline Gênero ( 1 masculino, 0 feminino) & $-2,23 *$ & $-0,18$ & $-2,57 *$ & 0,44 \\
\hline Estado (1 para o Paraná, 0 para outro) & $-2,44 *$ & $-0,60$ & $-1,38$ & - \\
\hline
\end{tabular}

Fonte: Resultado da pesquisa.

Nota: *Estatisticamente significativo a $5 \%$.

8 Também foi realizado o teste de distribuição Kolmogorov-Smirnov, no qual rejeitou-se Ha (valor da estatística igual a 2,14), indicando que, antes do pareamento, havia diferença entre os grupos (tratados e controle). 
É importante destacar que, depois do pareamento, as características do grupo tratado e de controle devem ser similares, de maneira que o teste de diferença entre médias de cada covariada não deve ser significativo. Se for, não é possível realizar a análise do impacto de ser cotista no abandono e no rendimento acadêmico especialmente porque os resultados podem decorrer de outras características que não da influência de ser cotista. Por isso, na Tabela 11 (última coluna), comparou-se os grupos de tratamento e controle após pareamento, realizando novamente o teste de diferença entre médias. Como corolário, as diferenças não foram estatisticamente significativas entre as médias das variáveis do grupo de tratamento versus o de controle, permitindo que se comparassem os dois grupos.

Após o pareamento do grupo de tratamento e de controle, aplicou-se o Propensity Score Matching visando a identificar o impacto de ser cotista no abandono e no rendimento dos acadêmicos. Na Tabela 12, tem-se o resultado para o abandono, o qual apresentou um efeito negativo e estatisticamente significativo para os alunos cotistas da UEPG (em torno de 0,08 pontos a menos de abandono para os cotistas), indicando um menor abandono dos cursos quando comparado ao abandono médio dos alunos não cotistas. Ou seja, os acadêmicos que entraram na instituição por meio das cotas tenderam a ter uma menor evasão do que os demais acadêmicos.

Nas análises preliminares, foi identificada certa diferença entre os resultados de abandono do grupo de cotistas e de não cotistas dos cursos de licenciatura versus bacharelado. Por isso, aplicou-se novamente o PSM para cada um desses grupos (Tabela 12).

No caso da licenciatura, o efeito relacionado ao abandono se apresentou sem significância estatística, ${ }^{9}$ indicando que, na média, os cotistas não tinham uma taxa de evasão inferior ou superior à obtida pelos não cotistas, sendo estatisticamente similar esse abandono. Assim, a evasão para os cursos de licenciatura independe da forma de ingresso dos alunos, não estando relacionada à entrada via cotas.

Talvez tal resultado decorra da menor renda média dos alunos de licenciatura, aproximando a condição social dos cotistas e dos não cotistas. Já no caso dos alunos que cursavam bacharelado, obteve-se significância estatística para o abandono, com um efeito negativo, inferindo-se que o abandono do grupo de cotistas era menor que o dos demais acadêmicos da UEPG.

9 Isso pode ser verificado por meio da estatística t (razão entre coeficiente obtido e o desvio padrão), não rejeitando a hipótese nula, ou seja, não há diferença entre os grupos no que se refere ao abandono. 
TABELA 12 - Efeito médio de ser cotista sobre o abandono escolar (a) e o rendimento acadêmico (b) da UEPG (1 se ingressou na instituição por meio da política de cotas, e 0 , caso contrário) de 2010 a 2017 - licenciatura, bacharelado e total

\begin{tabular}{|c|c|c|c|c|c|c|}
\hline \multirow[b]{2}{*}{ ALUNOS } & \multirow{2}{*}{$\begin{array}{l}\text { VARIÁVEL } \\
\text { RESULTADO }\end{array}$} & \multirow[b]{2}{*}{ ALGORITMO } & \multicolumn{2}{|c|}{ ABANDONO (A) } & \multicolumn{2}{|c|}{ RENDIMENTO (B) } \\
\hline & & & $\begin{array}{l}\text { EFEITO } \\
\text { MÉDIO }\end{array}$ & $\begin{array}{c}\text { ERRO } \\
\text { PADRÃO }\end{array}$ & $\begin{array}{l}\text { EFEITO } \\
\text { MÉDIO }\end{array}$ & $\begin{array}{c}\text { ERRO } \\
\text { PADRÃO }\end{array}$ \\
\hline \multirow[t]{2}{*}{ UEPG } & Abandono do curso & 3 vizinho & $-0,08 *$ & 0,038 & $0,06^{\mathrm{ns}}$ & 0,13 \\
\hline & & Caliper & $-0,07^{*}$ & 0,021 & $0,05^{\mathrm{ns}}$ & 0,12 \\
\hline \multirow[t]{2}{*}{ Licenciatura } & Abandono do curso & 3 vizinho & $-0,07^{\text {ns }}$ & 0,05 & $0,23^{\mathrm{ns}}$ & 0,18 \\
\hline & & Caliper & $-0,07^{\mathrm{ns}}$ & 0,04 & $0,20^{\mathrm{ns}}$ & 0,15 \\
\hline \multirow[t]{2}{*}{ Bacharelado } & Abandono do curso & 3 vizinho & $-0,13^{*}$ & 0,05 & $-0,08^{\mathrm{ns}}$ & 0,10 \\
\hline & & Caliper & $-0,11 *$ & 0,05 & $-0,09^{\text {ns }}$ & 0,09 \\
\hline
\end{tabular}

Fonte: Resultado da pesquisa.

Nota: * Estatisticamente significativo a 5\%; ns: não significativo.

Esses resultados se contrapõem ao mito de que os cotistas abandonariam mais facilmente a universidade. Para Bezerra e Gurgel (2012), essa é uma afirmação que a população em geral e os próprios acadêmicos acreditam, mas que diferentes trabalhos demonstram que é uma falácia. Os próprios autores, ao analisarem quatro cursos da Universidade Estadual do Rio de Janeiro, comprovaram que a evasão dos cotistas é praticamente a metade da auferida dos demais estudantes. Velloso (2009) também corrobora os achados deste estudo, identificando quase o dobro de evasão dos não cotistas na Universidade de Brasília (UnB). Igualmente, Silva (2017), analisando a Universidade Federal de Viçosa, reafirma a menor taxa de evasão de estudantes cotistas, ainda que estes permaneçam inseridos de forma precária nos espaços acadêmicos. Mais recentemente, Pinheiro, Pereira e Xavier (2021), ao fazerem uma revisão integrativa da literatura, também concluíram que há menor taxa de evasão e maior índice de diplomação de cotistas.

Em suma, pode-se afirmar que, no caso da UEPG e considerando os entrantes de 2010, o abandono não cresce com a adoção de ações afirmativas, ao contrário, no caso dos cursos de bacharelado, houve redução da evasão. Alguns autores inferem que esse resultado pode ser justificado por uma possível valorização dos cotistas por estarem numa universidade pública e de qualidade como a UEPG. Assim, não há prejuízo para a universidade em termos de vagas desperdiçadas quando se tem entrantes cotistas, pelo contrário, os resultados demonstram um melhor aproveitamento dessas vagas, resultando em alunos formados.

A segunda análise que foi feita refere-se ao rendimento acadêmico. Nesse caso, foram usadas as informações de todos os alunos que ingressaram na UEPG em 2010 e que concluíram o curso até 2017. Desse grupo, selecionou-se os cotistas (tratamento) e não cotistas (grupo de controle) e algumas covariadas, analisando-se se havia diferença estatística (Tabela 11). Após evidenciar que as características eram 
diferentes em ambos os grupos, ${ }^{10}$ fez-se novamente o teste após o pareamento, obtendo características similares entre o grupo tratado e o de controle. Diante dessas condições, aplicou-se o PSM.

Os resultados ratificam as hipóteses iniciais de não existência de diferenças estatísticas entre as notas médias dos graduados cotistas e não cotistas (Tabela 12). Mesmo quando subdivididos em licenciatura e bacharelado não se encontram efeitos médios estatisticamente significativos, ${ }^{11}$ indicando que, na média, o rendimento acadêmico final dos alunos que concluem os cursos na instituição é similar, independentemente de serem cotistas ou não cotistas. No trabalho feito por Velloso (2009), também se chegou à mesma conclusão, não havendo diferenças significantes entre o rendimento de cotistas e de não cotistas em dois terços dos cursos avaliados na UnB. Resultados similares foram verificados por Wainer e Melguizo (2018) e Valente e Berry (2017), os quais analisaram todos os cursos do Brasil por meio da nota do Exame Nacional de Desempenho dos Estudantes (Enade). Pinheiro, Pereira e Xavier (2021), ao fazer uma revisão integrativa de literatura, corroboram a similaridade no rendimento acadêmico obtido por cotistas e não cotistas no decorrer dos 17 anos de políticas afirmativas. Importante ressaltar que esses autores inferem a necessidade de uma avaliação contínua da política, especialmente pelos poucos resultados apurados para a realidade das instituições estaduais, foco desta pesquisa.

Nesse sentido, não há qualquer prejuízo para o padrão acadêmico da UEPG por ter uma seleção via cotas, não diminuindo comparativamente o rendimento final dos acadêmicos. Assim, os resultados mostram ser uma falácia o argumento de que a reserva de vagas defasaria a qualidade dos formados pelas universidades com sistemas de cotas, em que, mesmo subdividindo-os em bacharelado e licenciatura, ratificou-se a ausência de prejuízo da qualidade dos acadêmicos formados.

\section{CONSIDERAÇÕES FINAIS}

A formação de capital humano é extremamente importante para o desenvolvimento regional e para se auferir rendas individuais mais elevadas. Inserir os jovens em condição de pobreza na educação superior é a melhor maneira de gerar desenvolvimento, revertendo o círculo vicioso da pobreza de maneira endógena.

Entretanto, existem algumas posições contrárias a essa inclusão, focando especialmente no argumento de que não se teria um acompanhamento adequado desses

10 Diferença que foi ratificada pelo teste de distribuição Kolmogorov-Smirnov, no qual rejeitou-se $\mathrm{Ha}$ (valor da estatística igual a 1,98), indicando que, antes do pareamento, havia diferença entre os grupos (tratados e controle).

11 Isso pode ser verificado por meio da estatística t (razão entre coeficiente obtido e o erro padrão), não rejeitando a hipótese nula, ou seja, há similaridade entre os grupos no que se refere ao rendimento acadêmico. 
alunos, que desistiriam no decorrer do curso, ou de que resultaria na formação de profissionais menos competentes. A investigação feita na UEPG comprovou não serem verdadeiras essas argumentações, não havendo diferença de rendimento acadêmico e ocorrendo, inclusive, menos abandono de alunos cotistas.

Portanto, a política de cotas não prejudica a universidade pública nem seu objetivo principal, que é a formação de qualidade. Não apenas se consegue formar pessoas que estariam aquém do processo se não fosse a política, como também se obtêm um melhor aproveitamento das vagas de alguns cursos, dada a menor evasão universitária. Assim, reafirma-se o não prejuízo para as universidades públicas quanto à implementação das cotas públicas no que se refere à qualidade dos acadêmicos formados e a mitigação quanto ao abandono das vagas.

É claro que outras ações visando a eliminar as desigualdades, especialmente no que se refere à formação de base, devem ser implementadas conjuntamente com a política de cotas, construindo oportunidades iguais para um país que estruturalmente foi construído de maneira desigual.

\section{REFERÊNCIAS}

ANDRADE, C. Y. Acesso ao ensino superior no Brasil: equidade e desigualdade social. Revista Ensino Superior Unicamp, Campinas, SP, v. 1, n. 6, p. 1-20, 2012.

ARRIGONI, F. J. Gestão pública: busca da igualdade social a partir da ação afirmativa cota no ensino superior brasileiro. 2018. 307 f. Tese (Doutorado em Administração) - Fundação Getúlio Vargas, Rio de Janeiro, 2018.

BEZERRA, T. O. C.; GURGEL, C. A política pública de cotas na UERJ: desempenho e inclusão. In: ENCONTRO DE ADMINISTRAÇÃO PÚBLICA E GOVERNO, 5., 2012, Salvador. Anais [...]. Salvador: Associação Nacional de Pós-Graduação e Pesquisa em Administração, 2012. p. 1-15.

BITTAR, M.; ALMEIDA, C. E. M. de. Mitos e controvérsias sobre a política de cotas para negros na educação superior. Educar em Revista, Curitiba, v. 28, n. 1, p. 141-159, dez. 2006.

BLOM, A. L. H.; VERNER, D. Education, earnings, and inequality in Brazil, 1982-98. Peabody Journal of Education, v. 76, n. 3, p. 180-221, 2001.

CARVALHAES, C.; RIBEIRO, C. Estratificação horizontal da educação superior no Brasil. Tempo Social, São Paulo, v. 31, n. 1, p. 195-233, 2019.

COUTINHO, C. V. S.; PISTORE, A.; CRUZ, M. R.; CAMARGO, M. E. Perfil socioeconômico do aluno de graduação em Licenciatura e Tecnologia no ensino a distância: estudo de caso em um polo de apoio presencial da Serra Gaúcha. Scientia Plena, Aracaju, v. 9, n. 2, p. 1-13, fev. 2013.

DINIZ-PEREIRA, J. E. O ovo ou a galinha: a crise da profissão docente e a aparente falta de perspectiva para a educação brasileira. Revista Brasileira de Estudos Pedagógicos, Brasília, DF, v. 92, n. 230, p. 34-51, jan./abr. 2011. 
D’SOUZA, D. Illiberal Education. New York: Free Press, 1991.

FERNANDES, R.; FILHO, N. A. M. A evolução da desigualdade no Brasil metropolitano entre 1983 e 1997. Estudos Econômicos, São Paulo, v. 30, n. 4, p. 549-569, out./dez. 2000.

GUARNIERI, F. V. Cotas universitárias: perspectivas de estudantes em situação de vestibular. 2008. 146 f. Dissertação (Mestrado em Psicologia) - Faculdade de Filosofia, Ciências e Letras de Ribeirão Preto, Universidade de São Paulo, Ribeirão Preto, 2008.

HEINRICH, C.; MAFFIOLI, A.; VÁZQUEZ, G. A primer for applying Propensity-Score Matching: impact-evaluation guidelines. S.1.: Inter-american Development Bank, 2010.

INSTITUTO BRASILEIRO DE GEOGRAFIA E ESTATÍSTICA - IBGE. Pesquisa Nacional por Amostra de Domicílios. 2018. Disponível em: https://www.ibge.gov.br/estatisticas/sociais/trabalho/9171pesquisa-nacional-por-amostra-de-domicilios-continua-mensal.html? =\&t=microdados. Acesso em: dez. 2018.

LIMA E SILVA, A.; MOTA, R.; LIMA, J.; QUEIROZ, F. A influência da escolaridade dos pais e da renda familiar no desempenho dos candidatos do Enem. In: ENCONTRO NACIONAL DE ENGENHARIA DE PRODUÇÃO, 37, 2017, Joinville. Anais [...]. Joinville: Associação Brasileira de Engenharia de Produção, 2017. Disponível em: http://www.abepro.org.br/biblioteca/TN_ STO_243_410_32201.pdf. Acesso em: 14 dez. 2021.

LUCAS, R. E. On the mechanics of economic development. Jounal of Monetary Economics, v. 22, n. 1, p. 3-42, 1988.

MAZZETTO, S. E.; CARNEIRO, C. C. B. e S. Licenciatura em Química da UFC: perfil socioeconômico, evasão e desempenho dos alunos. Química Nova, São Paulo, v. 25, n. 6, p. 12041210, 2002.

MIRANDA, E. A. A política de cotas no Instituto Federal de Educação, Ciência e Tecnologia do Sudeste de Minas Gerais: análise do acesso e da permanência. 2017. 224f. Dissertação (Mestrado) - Programa de Pós-Graduação em Educação, Universidade Federal de Viçosa, Viçosa, MG, 2017. Disponível em: https://locus.ufv.br//handle/123456789/24337. Acesso em: 20 abr. 2019.

NASCIMENTO, J. D.; PEREIRA, R. S. O perfil dos estudantes cotistas da UFBA: um estudo descritivo. In: ENCONTRO DE PESQUISA EDUCACIONAL DO NORTE E NORDESTE, 22, 2014, Natal. Anais [...]. Natal: Associação Nacional de Pós-Graduação e Pesquisa em Educação, 2014.

PINHEIRO, D.; PEREIRA, R.; XAVIER, W. Impactos das cotas no ensino superior: um balanço do desempenho dos cotistas nas universidades estaduais. Revista Brasileira de Educação, Rio de Janeiro, v. 26, e260020, 2021. DOI: 10.1590/S1413-24782021260020

QUEIROZ, D. M. Universidade e desigualdade: brancos e negros no ensino superior. Brasília: Liber Livro, 2004.

ROMER, P. M. Increasing Returns and Long-Run Growth. Journal of Political Economy, v. 94, n. 5, p. 1002-1037, 1986.

SANTOS, J. T.; QUEIROZ, D. M. Affirmative action and higher education in Brazil. International Encyclopedia of Education, v. 1, n. 1, p. 760-766, 2010. 
SILVA, B. C. Desconstruindo mitos: meritocracia e a lei de cotas. 2017. 151 f. Dissertação (Mestrado em Administração) - Universidade Federal de Viçosa, Viçosa, 2017.

SOWELL, T. Affirmative action around the world: an empirical study. New Haven; London: Yale University Press, 2004.

UNIVERSIDADE ESTADUAL DE PONTA GROSSA. Resolução n. 9 de 26 de abril de 2006. Disponível em: https://www2.uepg.br/prae/wp-content/uploads/sites/18/2020/11/3_Reserva-de-vagas-nosProcessos-Seletivos-da-UEPG.pdf. Acesso em: jan. 2019.

VALENTE, R. R.; BERRY, B. J. L. Performance of students admitted through affirmative action in Brazil. Latin American Research Review, v. 52, n. 1, p. 18-34, 2017.

VELLOSO, J. Cotistas e não-cotistas: rendimento de alunos da Universidade de Brasília. Cadernos de Pesquisa, São Paulo, v. 39, n. 137, p. 621-644, maio/ago. 2009.

VELLOSO, J.; CARDOSO, C. B. Evasão na educação superior: alunos cotistas e não cotistas na Universidade de Brasília. In: REUNIÃO ANUAL DA ASSOCIAÇÃO NACIONAL DE PÓS-GRADUAÇÃO E PESQUISA EM EDUCAÇÃO, 31., 2008, Caxambu. Anais [...]. Caxambu: Associação Nacional de Pós-Graduação e Pesquisa em Educação, 2008. p. 1-15.

VIEIRA, M. A.; TENÓRIO, R. M. Impacto da escolaridade dos pais e nível socioeconômico familiar nos resultados de testes cognitivos. 2014. Disponível em: http://www.anpae.org.br/IBERO_AMERICANO_ IV/GT3/GT3_Coimunicacao/MarcosAntonioVieira_GT3_integral.pdf.

Acesso em: nov. 2019.

WAINER, J.; MELGUIZO, T. Políticas de inclusão no ensino superior: avaliação do desempenho dos alunos baseado no Enade de 2012 a 2014. Educação e Pesquisa, São Paulo, v. 44, e162807, 2018. DOI: $10.1590 / \mathrm{S} 1517-9702201612162807$

\section{APÊNDICE}

\section{GRÁFICO A- Função Densidade do Propensity Score - Método de pareamento "três vizinhos mais próximos com reposição"}

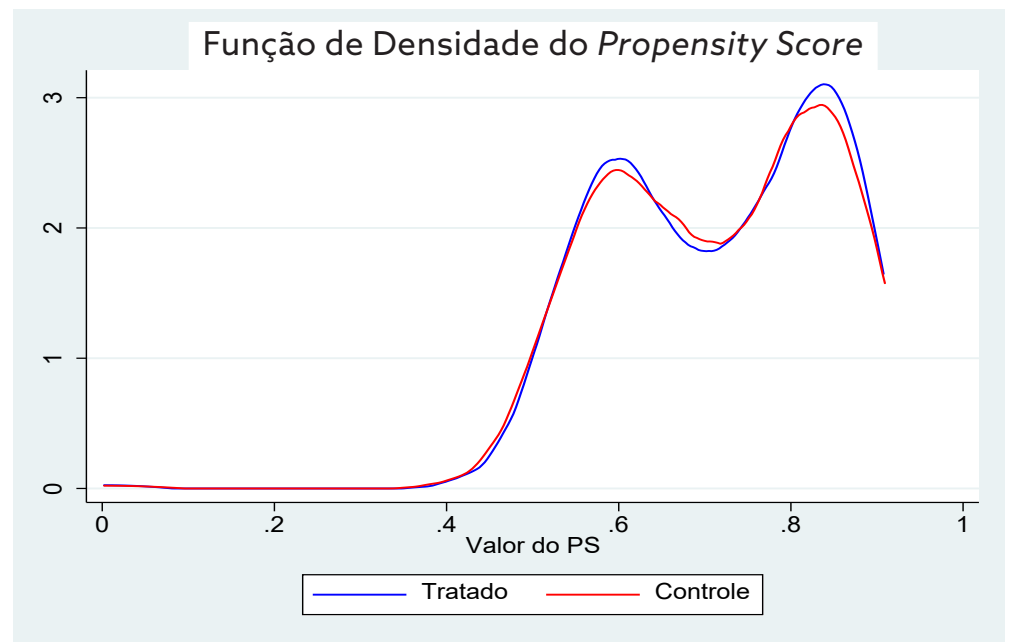

Fonte: Elaboração da autora. 


\section{COMO CITAR ESTE ARTIGO}

RAIHER, Augusta Pelinski. Políticas de cotas na UEPG: análise do abandono e do rendimento acadêmico. Estudos em Avaliação Educacional, São Paulo, v. 33, e08475, 2022. https://doi.org/10.18222/eae.v33.8475

Recebido em: 17 MARÇO 2021

Aprovado para publicação em: 1 DEZEMBRO 2021 